\title{
Comparison of 2507 Duplex and $28 \%$ Cr- Austenitic Stainless Steel Corrosion Behavior for High Pressure and High Temperature (HPHT) in Sour Service Condition with C-ring Experiment
}

\author{
Harris Prabowo ${ }^{1,2}$, Badrul Munir ${ }^{1}$, Yudha Pratesa ${ }^{1}$, Johny W. Soedarsono ${ }^{1 *}$ \\ 1 Department of Metallurgy and Materials, Faculty of Engineering, Universitas Indonesia, Kampus Baru, 16425 Depok, \\ P.O.B. 16425, Indonesia \\ 2 Pertamina Research and Technology Center (RTC), 13920 Jakarta, P.O.B. 12950, Indonesia \\ * Corresponding author, e-mail: jwsono@metal.ui.ac.id
}

Received: 28 November 2020, Accepted: 30 April 2021, Published online: 05 July 2021

\begin{abstract}
The scarcity of oil and gas resources made High Pressure and High Temperature (HPHT) reservoir attractive to be developed. The sour service environment gives an additional factor in material selection for HPHT reservoir. Austenitic $28 \mathrm{Cr}$ and super duplex stainless steel 2507 (SS 2507) are proposed to be a potential materials candidate for such conditions. C-ring tests were performed to investigate their corrosion behavior, specifically sulfide stress cracking (SSC) and sulfide stress cracking susceptibility. The C-ring tests were done under $2.55 \% \mathrm{H}_{2} \mathrm{~S}$ (31.48 psia) and $50 \% \mathrm{CO}_{2}$ (617.25 psia). The testing was done in static environment conditions. Regardless of good SSC resistance for both materials, different pitting resistance is seen in both materials. The pitting resistance did not follow the general Pitting Resistance Equivalent Number (PREN), since SS 2507 super duplex (PREN > 40) has more pitting density than $28 \mathrm{Cr}$ austenitic stainless steel (PREN < 40). SS 2507 super duplex pit shape tends to be larger but shallower than $28 \mathrm{Cr}$ austenitic stainless steel. $28 \mathrm{Cr}$ austenitic stainless steel has a smaller pit density, yet deeper and isolated.
\end{abstract}

Keywords

C-ring test, High Pressure and High Temperature (HPHT), austenitic $28 \mathrm{Cr}$, super duplex 2507

\section{Introduction}

The amount of oil and gas reserves in Indonesia is currently declining. So far, various reservoirs in the main zone have been produced, so that for the sustainability of new oil and gas sources the future direction of developers are High-Pressure and High Temperature (HPHT) wells. With the active geological conditions in Indonesia, the existence of reserves with HPHT well types are very big. High Pressure (HP) typically refers to borehole pressures between 10,000-20,000 psi, while High Temperature (HT) refers to borehole temperatures between $300-400{ }^{\circ} \mathrm{F}$ (149-204 ${ }^{\circ} \mathrm{C}$ ). Our previous case study showed this environment is severe for carbon steel [1].

HPHT operating conditions are exacerbated by the presence of corrosive gases such as $\mathrm{H}_{2} \mathrm{~S}$ and $\mathrm{CO}_{2}$, as well as brine fluids that contain a lot of chlorides. To support the success of this project, corrosion-resistant materials are needed for Oil Country Tubular Goods (OCTG) applications that can withstand high temperature and high-pressure situations. For high-pressure applications, the development of steel-based materials is carried out by adding a heat treatment process to obtain a fine tempered martensite steel structure. This method succeeded in creating high strength steel above 110 ksi SMYS [2, 3].

However, the main problem of martensite steel is their low crack resistance due to a decrease in KISCC value due to Chromium and manganese addition. Asahi and Ueno [4] discovered the fact that the addition of Chromium $>1 \%$ reduced the value of stress intensity factor (KISSC) due to the higher $\mathrm{M}_{23} \mathrm{C}_{6}$ carbides numbers. The effect of adding $\mathrm{M}_{23} \mathrm{C}_{6}$ carbide can be minimized by adding Niobium $(\mathrm{Nb})$ to make spheroidization of $\mathrm{M}_{23} \mathrm{C}_{6}$ carbide [5].

Martensitic steel material is not an attractive option for high-pressure conditions with high $\mathrm{H}_{2} \mathrm{~S}$ levels because of the possibility of sulfide cracking. For conditions with 
high $\mathrm{H}_{2} \mathrm{~S}$, the materials commonly used in HPHT well operations are Nickel-based alloy and titanium-based alloy $[6,7]$. The combination of corrosion resistance and strength offered by Titanium and Nickel alloy as a clad material or solid material. Hargrave et al. [8] proposed titanium alloys for sour production environments, completion brines, and acids. A high strength titanium alloy called Ti-6246 (Ti-6Al-2Sn-4Zr-6Mo; UNS R56260) could work for HPHT services. However, the price for titanium and nickel is quite high and its availability is rarely available in the market. For this reason, several alternative Corrosion Resistance Alloys (CRA) are used, such as the duplex stainless steel or high-Cr austenitic stainless steel.

Duplex stainless steel is a material that offers a good combination of mechanical properties and corrosion resistance supported at a fairly economical price. High mechanical strength in the duplex is caused by the combination of ferrite and austenite phases in stainless steel. Ferrite gives an optimal increase in the amount of 22-28\% [9]. Nowadays, many studies have intensively analyzed the effect of microstructure on duplex corrosion resistance. Moura et al. [10] found that the sigma phase is the most susceptible phase for pitting corrosion in duplex stainless steel. On the other hand, Tan et al. [11] showed the pitting susceptibility is dependent on pitting resistance equivalent number from ferrite or austenite phase in hyperduplex [12]. Besides pitting corrosion, duplex stainless steel also prone to stress corrosion cracking. Van Gelder et al. [13] found that duplex stainless steel is susceptible to stress corrosion cracking at a temperature around $60-100{ }^{\circ} \mathrm{C}$ and when subjected to a slow plastic strain rate in their open circuit potential.

Conventional austenitic stainless steel is not commonly used in HPHT and brine environments due to the low SCC resistivity. Therefore, the development of austenitic material is carried out with the use of more Nickel and Molybdenum, which is commonly known as super austenitic stainless steel such as $28 \mathrm{Cr}$ austenitic stainless steel. $28 \mathrm{Cr}$ austenitic stainless steel contains more Chromium than grade 304 and 316 SS. The amount of nickel and molybdenum is increased to keep the austenite phase stable at room temperature.

The studies that have been mentioned earlier were performed only in chloride and HPHT services, and limited was made in high pressure and high temperature with sour service condition. This study will compare $2507 \mathrm{SS}$ and $28 \%$ Cr-Austenitic stainless steel in corrosive gases such as $\mathrm{CO}_{2}$ and $\mathrm{H}_{2} \mathrm{~S}$ as well as chloride ions in the solution. Both of the materials were selected and compared their suitability in the HPHT-sour services condition. A comparison of the ferrite-austenite dual-phase and single austenitic phase will be discussed in this paper. The test was performed using the C-ring method in the autoclave according to the HPHT well-operating pressure.

\section{Methods}

\subsection{Specimen preparation}

C-ring specimen was prepared following NACE TM01772016 method C. The specimens were cut approximately $15 \mathrm{~mm}$ in length from the whole tube to full wall thickness. Stainless steel bolts were used to load the specimens and were electrically isolated from the specimen using inert polyether-ether ketone (PEEK) bushes.

The testing specimens were made by using two materials, $28 \mathrm{Cr}$ austenitic SS and SS 2507 super duplex specimens were loaded to a strain equivalent to $100 \%$ of the $0.2 \%$ proof stress, measured by strain gauge and determined at the test temperature of $122^{\circ} \mathrm{C}$. After loading, the strain gauges were removed, and the specimens were thoroughly cleaned. The final specimen arrangement is shown in Fig. 1.

\subsection{Testing parameters}

Testing was conducted using NACE TM0177-2016 and ISO15156 part 3 Annex B guidelines. Before the testing, the specimen was cleaned with deionized water and followed by acetone to remove the excessive water. The specimen was dried out in warm air. The testing was carried out under autoclave to maintain the pressure around $1220 \mathrm{psig}$, temperature $252^{\circ} \mathrm{F}\left(122^{\circ} \mathrm{C}\right)$, and chloride content $10,000 \mathrm{ppm}$.

The chloride-containing solution was made using bidest solutions and was purged by Nitrogen for deaeration. The oxygen content was maintained below $10 \mathrm{ppb}$. To simulate the sour service condition, the environment was saturated with $2.55 \% \mathrm{H}_{2} \mathrm{~S}(31.48 \mathrm{psia})$ and $50 \% \mathrm{CO}_{2}$ (617.25 psia). Pressure and temperature were monitored during the experiment (Fig. 2).

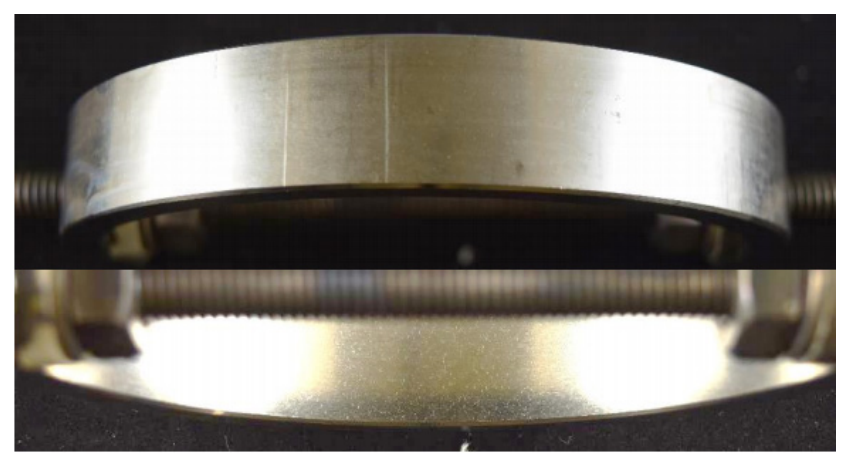

Fig. 1 C-ring test specimens 


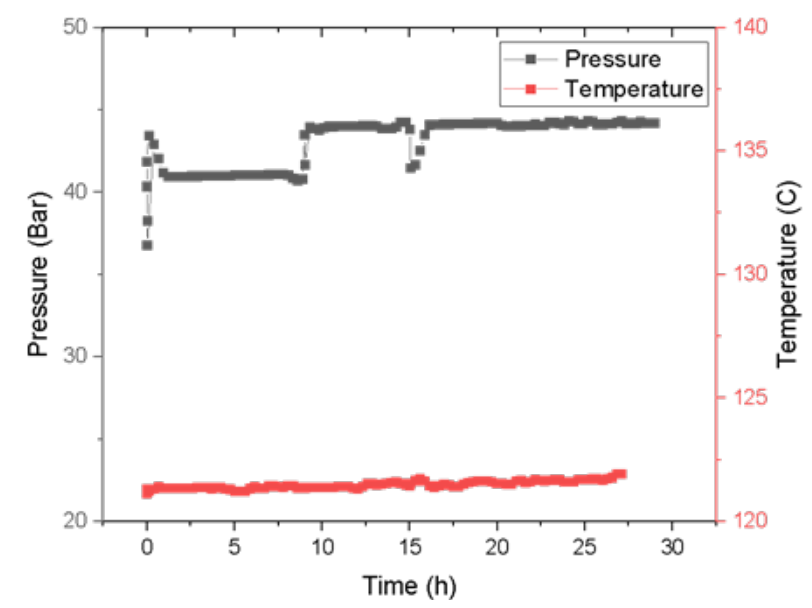

Fig. 2 Pressure and temperature monitoring result during C-ring test

Metallography was performed using electroetching. $\mathrm{KOH}$ etchant was given for duplex stainless steel and oxalic acid $10 \%, 2.5 \mathrm{~V}$ dc for austenitic stainless steel, stainless steel and oxalic acid $10 \%, 2.5 \mathrm{~V}$ dc for austenitic stainless steel.

The specimens were rinsed in deionized water to remove the residual salt solution and get a better visual examination. The after-test C-ring specimens were analyzed by low-magnification optical microscopy. All specimens were cut and prepared for crack examination at x100 magnifications.

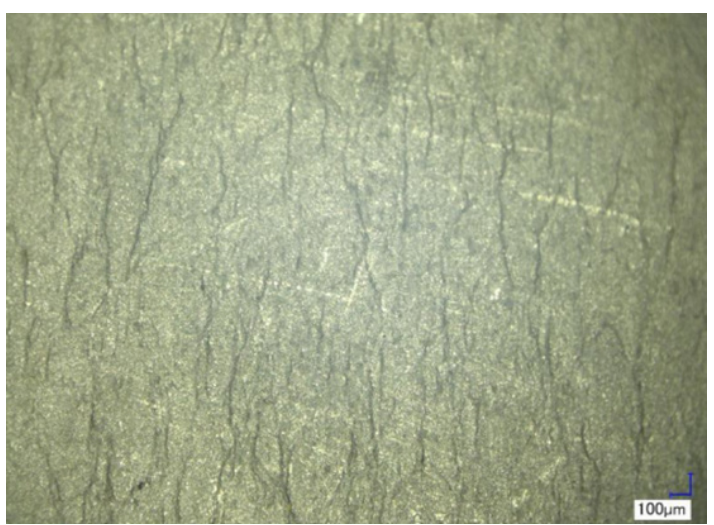

(a)

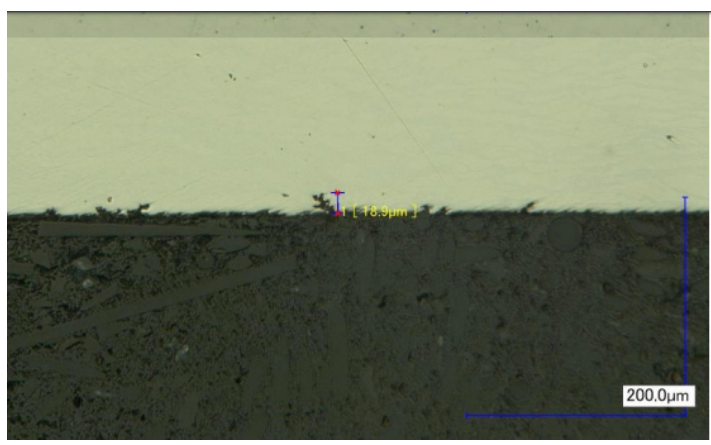

(c)

\section{Results and discussion}

Examination of the tested C-ring samples of $28 \mathrm{Cr}$ and SS 2507 found light corrosion on both materials. The corrosion product is found in the external and internal surfaces of the SS 2507 samples. From the visual examination, various corrosion phenomena are found on the surface of SS 2507 materials. The surface indicates surface cracking, as shown in Fig. 3(a). Besides the surface cracking indication, pitting corrosion and intergranular corrosion are also found (Fig. 3(b), (c), and (d)).

The surface cracks indications in 2507 duplex stainless steel did not penetrate to the subsurface of the metal, and there is no sign of propagation from the base of the pits. The pitting depth average is $17.8 \mu \mathrm{m}$, while the maximum and minimum pits are $20.4 \mu \mathrm{m}$ and $10.9 \mu \mathrm{m}$ respectively. This result showed that the pits are wide and shallow. The examination shows there were more pitting sites present on the 2507 duplex stainless steel; hence it would indicate that SS 2507 has a lower resistance to corrosion compared to the $28 \mathrm{Cr}$ stainless steel in the testing environment.

From the cross-section examination, the surface crack indication was formed due to selective corrosion in duplex stainless steel, most probably from the existend of dualphase stainless steel which yields a micro galvanic corrosion phenomenon [13].

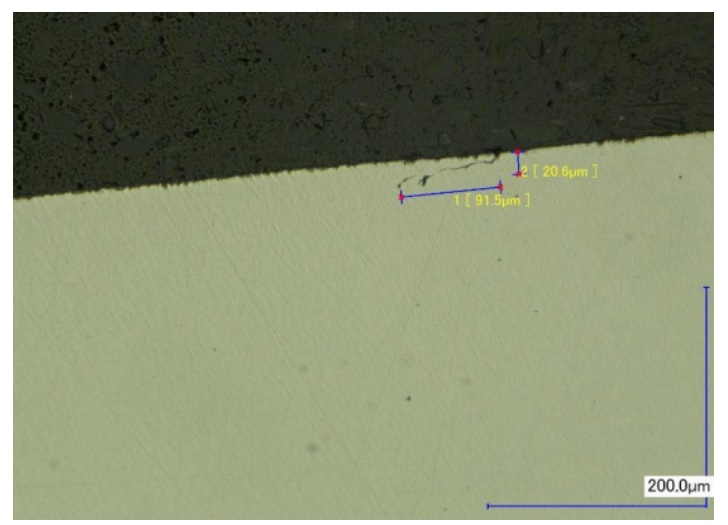

(b)

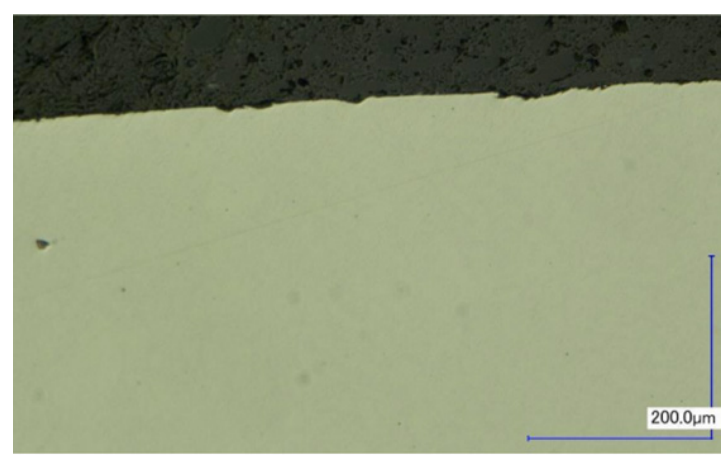

(d)

Fig. 3 Macrograph result of 2507 duplex stainless steel (a) surface examination- surface crack indication, (b-d) pit morphologies 
Pitting Resistance Equivalent Number is used to compare pitting susceptibility of each stainless-steel material based on the composition of chromium, molybdenum and nitrogen, as shown in the Eq. (1).

$$
P R E N=\% C r+3.3 \times \% M o+16 \times \% N
$$

Based on Pitting Resistance Equivalent Number, SS 2507 super duplex has a PREN number of around more than 42 , while $28 \mathrm{Cr}$ austenitic SS has 38.5. Based on this value, SS 2507 super duplex should be more resistant for pitting formation towards austenitic SS. However, in this case, micro-galvanic corrosion is more influential in duplex stainless steel causing a local dissolution in a specific phase. This result is following the Garfias-Mesias et al. [14]. results that showed the ferrite phase corroded faster than austenite in duplex stainless steel even though PREN in the ferrite was higher than austenite. This phenomenon is affected by element distribution in each of the phases $[14,15]$.

The Austenitic $28 \mathrm{Cr}$ stainless steel did not show any surface cracking. The pits are isolated, depth, and sharp (Fig. 4(a) and (b)). However, the number of pits was lower than the duplex SS 2507 super duplex, as shown in Fig. 4(b) and (c). There is no indication of crack propagation from the surface or bottom of the pit (Fig. 4(c)). Austenitic $28 \mathrm{Cr}$ stainless steel consists of only the austenitic phase. There is no different distribution of $\mathrm{Cr}$ in this material, such as in duplex stainless steel. Hence, the pitting corrosion resistance is better than SS 2507.

Based on the C-ring test, both duplex 2507 and austenitic $28 \mathrm{Cr}$ stainless steel are a potential candidate for highpressure and high-temperature service in a sour services environment. Both of the materials did not show sulfide stress cracking.

In order to prove the effect phase and microstructure contained in both of the alloys, a metallography test was performed on the cross-section of the sample. Fig. 5(a) shows pits propagated in the center of the ferrite phase in SS 2507 super duplex. Table 1 shows the size of the detected pit in both off the alloy. The pit size is the average number of the pit depth from each alloy. It is clearly seen that the 2507 duplex stainless steel are more prone to pitting than austenitic stainless steel.

\section{Conclusion}

C-ring tests were performed in SS 2507 super duplex stainless steel and Austenitic $28 \mathrm{Cr}$ SS to investigate their corrosion behavior and sulfide stress cracking (SSC) susceptibility. Regardless of good SSC resistance for both materials, different pitting resistance is seen in both materials.

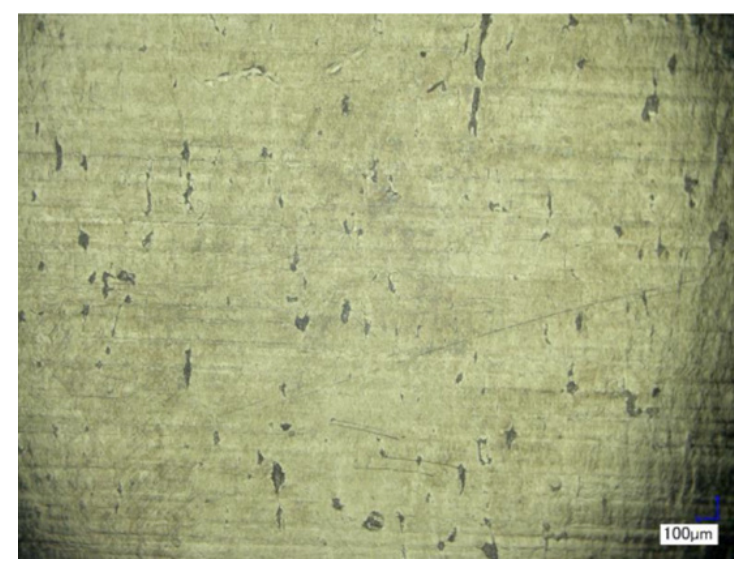

(a)

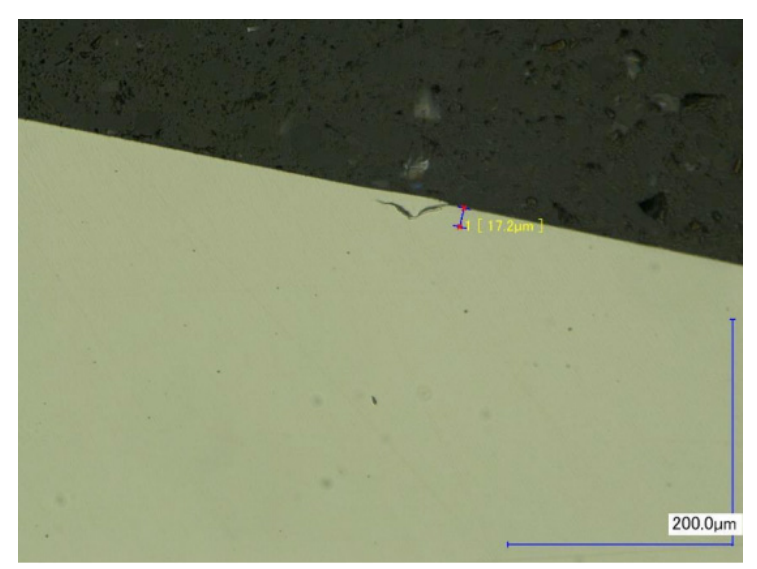

(b)

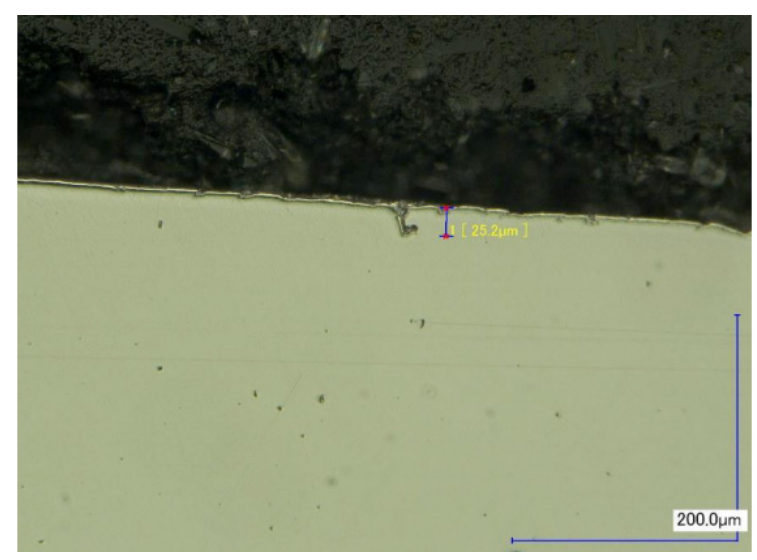

(c)

Fig. 4 Macrograph result of $28 \mathrm{Cr}$ austenitic stainless steel (a) surface examination- isolated pit, (b) and (c) pit morphologies

Duplex stainless steel is prone to pitting corrosion and the pit shape tends to be larger but shallower than $28 \mathrm{Cr}$ austenitic stainless steel. $28 \mathrm{Cr}$ austenitic stainless steel has a smaller pit density, but it deeper and isolated. Optical micrography results deny the surface cracking indication in duplex stainless steel and prove that the selective corrosion causes a crack-like feature in duplex stainless steel. The selective corrosion is caused by the micro galvanic 


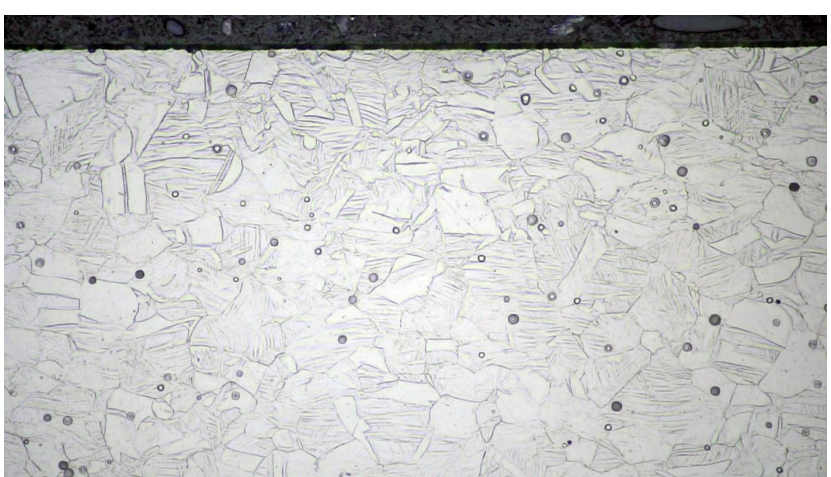

(a)

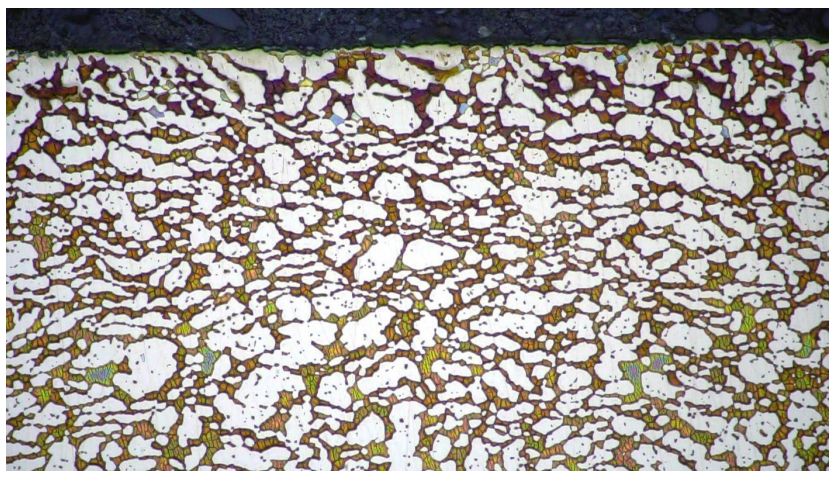

(b)

Fig. 5 (a) Preferential corrosion in ferrite phase in SS2507; (b) and shallow pit in austenitic stainless steel

\section{References}

[1] Prabowo, H., Pratesa, Y., Tohari, A., Mudakir, A., Munir, B., Soedarsono, J. W. "Failure analysis of geothermal perforated casing tubing in $\mathrm{H} 2 \mathrm{~S}$ and $\mathrm{O} 2$ containing environment", Eastern-European Journal of Enterprise Technologies, 6(12(108), pp. 72-78, 2020. https://doi.org/10.15587/1729-4061.2020.215163

[2] Leyer, J., Sutter, P., Marchebois, H., Bosch, C., Orlans, B., Kulgemeyer, A. "Ssc Resistance Of A 125 Ksi Steel Grade In Slightly Sour Environments", In: CORROSION 2005, NACE International, Houston, TX, USA, Rep. NACE-05088, 2005.

[3] Di Schino, A., Porcu, G., Scoppio, L., Longobardo, M., Turconi, G. L. "Metallurgical Design and Development of C125 Grade for Mild Sour Service Application", In: CORROSION 2006, NACExpo, San Diego, CA, USA, Rep. NACE-06125, 2006.

[4] Asahi, H., Ueno, M. "Effect of Austenite Grain Size on Sulfide Stress Cracking Resistance of Low Alloy Martensitic Steels", ISIJ International, 32(9), pp. 1021-1026, 1992.

https://doi.org/10.2355/isijinternational.32.1021

[5] Taneike, M., Sawada, K., Abe, F. "Effect of carbon concentration on precipitation behavior of M23C6 carbides and MX carbonitrides in martensitic $9 \mathrm{Cr}$ steel during heat treatment", Metallurgical and Materials Transactions A, 35(4), pp. 1255-1262, 2004.

https://oi.org/10.1007/s11661-004-0299-x
Table 1 Size of detected pits in $28 \mathrm{Cr}$ and SS 2507

\begin{tabular}{lcc}
\hline Alloy & Sample identity & Pit size $(\mu \mathrm{m})$ \\
\hline & 1 OD & \pm 20 \\
2507 duplex & 1 ID & \pm 17 \\
stainless steel & 2 OD & \\
& 3 OD & \pm 20 \\
& 3 ID & \\
& 1 OD & \\
28 Cr Austenitic & 1 ID & \\
stainless steel & 2 OD & \\
& 2 ID & \\
& 3 OD & \\
& 3 ID & \\
\hline
\end{tabular}

corrosion between ferrite and austenite phase regardless of duplex stainless steel has a higher PREN than $28 \mathrm{Cr}$. No crack propagation originating from pitting was found in both of the materials.

\section{Acknowledgement}

The authors would thankfully recognize the data and financial support from PT Pertamina (Persero), LPDP and Universitas Indonesia.

[6] Gonzalez, M. E., Maskos, K., Hargrave, R., Kuberry, J. L., Reeves, D. E., Grauman, J., Skogsberg, J., Ali, S. A. "Titanium Alloy Tubing for HP/HT Applications", In: SPE Annual Technical Conference and Exhibition, Denver, CL, USA, 2008, Article number: SPE-115708-MS.

https://doi.org/10.2118/115708-MS

[7] Thodla, R., Cao, L., Hawk, J., Ziomek-Moroz, M. "Relationship between Localized Corrosion and Stress Corrosion Cracking of Nickel Based Alloys in HPHT Oil and Gas Environments", In: CORROSION 2016, Vancouver, Canada, 2016, Article number: NACE-2016-7113.

[8] Hargrave, B., Gonzalez, M., Maskos, K., Skogsberg, J., Grauman, J. "Titanium Alloy Tubing For Hpht Octg Applications", In: CORROSION 2010, San Antonio, TX, USA, 2010, Article number: NACE-10318.

[9] Rana, R., Loiseaux, J., Lahaye, C. "Microstructure, Mechanical Properties and Formability of a Duplex Steel", Materials Science Forum, 706-709, pp. 2271-2277, 2012.

https://doi.org/10.4028/www.scientific.net/MSF.706-709.2271

[10] Moura, V. S., Lima, L. D., Pardal, J. M., Kina, A. Y., Corte, R. R. A., Tavares, S. S. M. "Influence of microstructure on the corrosion resistance of the duplex stainless steel UNS S31803", Materials Characterization, 59(8), pp. 1127-1132, 2008. https://doi.org/10.1016/j.matchar.2007.09.002 
[11] Tan, H., Jiang, Y., Deng, B., Sun, T., Xu, J., Li, J. "Effect of annealing temperature on the pitting corrosion resistance of super duplex stainless steel UNS S32750", Materials Characterization, 60(9), pp. 1049-1054, 2009.

https://doi.org/10.1016/j.matchar.2009.04.009

[12] Deng, B., Jiang, Y., Gong, J., Zhong, C., Gao, J., Li, J. "Critical pitting and repassivation temperatures for duplex stainless steel in chloride solutions", Electrochimica Acta, 53(16), pp. 5220-5225, 2008. https://doi.org/10.1016/j.electacta.2008.02.047

[13] Van Gelder, K., Erlings, J. G., Damen, J. W. M., Festen, M. M. "Limiting Conditions for the Application of Duplex Stainless Steel and Corrosion-Resistant Clad Materials in Sour Service", presented at International Conference Pipe Technology, Rome, Italy, Nov. 17, 1987.
[14] Garfias-Mesias, L. F., Sykes, J. M., Tuck, C. D. S. "The effect of phase compositions on the pitting corrosion of $25 \mathrm{Cr}$ duplex stainless steel in chloride solutions", Corrosion Science, 38(8), pp. $1319-1330,1996$. https://doi.org/10.1016/0010-938X(96)00022-4

[15] Lee, J. S., Jeon, S. H., Park, Y. S. "Effects of Solution Annealing Temperature on the Galvanic Corrosion Behavior of the Super Duplex Stainless Steels", Journal of Materials Engineering and Performance, 22(2), pp. 557-562, 2013.

https://doi.org/10.1007/s11665-012-0255-7 